\title{
Serious Fungal Diseases in the Republic of Usbekistan
}

DOI:

10.1007/s10096-017-2926-7

\section{Document Version}

Accepted author manuscript

Link to publication record in Manchester Research Explorer

\section{Citation for published version (APA):}

Tilavberdiev, S. A., Denning, D., \& Klimko, N. N. (2017). Serious Fungal Diseases in the Republic of Usbekistan. European Journal of Clinical Microbiology and Infectious Diseases, 36(6), 925-929.

https://doi.org/10.1007/s10096-017-2926-7

\section{Published in:}

European Journal of Clinical Microbiology and Infectious Diseases

\section{Citing this paper}

Please note that where the full-text provided on Manchester Research Explorer is the Author Accepted Manuscript or Proof version this may differ from the final Published version. If citing, it is advised that you check and use the publisher's definitive version.

\section{General rights}

Copyright and moral rights for the publications made accessible in the Research Explorer are retained by the authors and/or other copyright owners and it is a condition of accessing publications that users recognise and abide by the legal requirements associated with these rights.

\section{Takedown policy}

If you believe that this document breaches copyright please refer to the University of Manchester's Takedown Procedures [http://man.ac.uk/04Y6Bo] or contact uml.scholarlycommunications@manchester.ac.uk providing relevant details, so we can investigate your claim.

\section{OPEN ACCESS}




\section{SERIOUS FUNGAL DISEASES IN THE REPUBLIC OF UZBEKISTAN}

\section{Tilavberdiev Sh.A. ${ }^{1}$, Denning D.W. ${ }^{2}$, Klimko N.N. ${ }^{3}$}

${ }^{1}$ Republican Center of Control of AIDS, the Republic of Uzbekistan, Tashkent

2 The University of Manchester, UK in association with the LIFE program at www.LIFE-worldwide.org

${ }^{3}$ I. Metchnikov North-Western State Medical University, St. Petersburg, Russia

Correspondence: Prof. Nikolai Klimko, I. Metchnikov North-Western State Medical University, 1/28 Santiago-de-Cuba str., St.-Petersburg 194291, Russia.

Tel. +7 812 3035146. Fax: +7 8123035146 .

E-mail: n_klimko@mail.ru

Keywords: LIFE PROGRAM, mycoses, fungal diseases, Republic of Uzbekistan

Running title: Fungal diseases in Uzbekistan 


\begin{abstract}
We have undertaken the first and preliminary estimation of severe and chronic mycotic diseases in the Republic of Uzbekistan using a model proposed by LIFE (Leading International Fungal Education). Calculation was carried out based on data from 2014. Published results describing mycoses in Uzbekistan were identified. In the absence of published or official data, information about the frequency of mycoses from scientific literature elsewhere in groups at risk of development of fungal infections were taken into account. We also utilized methodology used in analogous estimations of mycoses in the Russian Federation. We estimate that 536,978 people $(1,8 \%$ of the population) were affected by severe and chronic mycotic diseases. In 2014 there were 12,351 cases of acute fungal diseases and 524,627 cases of chronic fungal diseases. The most frequent problems were recurrent vulvovaginal candidiasis (513,600 cases), trichophytosis of the scalp $(6,414)$, and relapsed oral candidiasis $(4,950)$. Results of investigation indicate a significant prevalence of mycoses in the Republic of Uzbekistan.
\end{abstract}




\section{Introduction}

Mycoses have been increasing in recent years related to better recognition and increasing numbers of immunocompromised patients [1-4]. Many diagnostic and therapeutic advances have been made. From a public health perspective, an estimate of the burden of infection, its health economic consequences, and contributions to morbidity and mortality are critical to a rounded assessment of the most pressing needs of different patient groups and priority setting. Such an estimate has never been previously attempted for the Republic of Uzbekistan.

To compare and coordinate epidemiological data and link it with health professional education, the Fungal Infection Trust set up LIFE (Leading International Fungal Education) [5]. Some mycotic diseases cannot be estimated from underlying disease and risk, such as fungal keratitis and tinea capitis, and so estimates of these infections tend to reflect incidence or prevalence in one or a small number of localities, whereas infection rates in, for example, transplant recipients, can be estimated with a much higher degree of precision. Using this approach we have attempted an estimate of the burden of serious mycoses in Uzbekistan.

\section{Material and methods}

The calculations by the LIFE modeling approach have been performed using indicators and data from 2014. Published data on mycoses in Uzbekistan were studied. In the absence of official data, we estimated the size of each at risk group and then assessed the national prevalence and morbidity rates using data from the literature. Similar approaches used in the Russian Federation (RF) guided our estimates [1].

Statistical data about number and composition of the population of Uzbekistan were obtained from the statistics of the Ministry of Health $[8,9]$. The evaluation of the morbidity due to mycoses of the scalp was based on data from the Republican Specialized Research Practical Medical Center of Dermatology and Venereology (RSRPMC). The number of women of reproductive age (15-50 years) in Uzbekistan in 2014 accounted for 8.56 million [8]. The number of patients with recurrent vulvovaginal candidiasis was calculated using anonymised, randomly collected data from 
international epidemiological investigations showing that this disease occurs in $6 \%$ of women [10].

Information on the number of patients with HIV/AIDS in Uzbekistan was received from the report of the Republican Center of Control of AIDS [11]. Oropharyngeal candidiasis has been identified in $90 \%$ of HIV-infected patients with CD4+ $<0,2 \times 10^{9} / 1$, and candidal oesophagitis - in $20 \%$ of HIV-infected patients with $\mathrm{CD} 4+<0,2 \times 10^{9} / 1+5 \%$ of those on ARVs [5].

According to Klimko et al [1] the frequency of candidemia and Candida peritonitis accounted for 0.37 per 1000 hospitalized patients. The total number of hospitalized patients in 2014 were obtained from data of the Ministry of Health [9].

The estimation of hematological diseases was guided by the data of Research Institute of Hematology and Blood Transfusion (RIH and BT) of the Ministry of Health. The risk of the development of invasive aspergillosis (IA) in patients with hematological diseases was calculated as described elsewhere $[1,19,20]$. The frequency of mucormycosis development in the general population was calculated using data of prevalence of acute myeloid leukemia in RIH and BT of MH of RUz, supplemented by general population data.

The estimation of COPD frequency was guided by statistical data and local publications $[6,12]$.

Data on the annual incidence of pulmonary tuberculosis were received from the reports of the Ministry of Health [9] and WHO documents [13]. The annual incidence of chronic pulmonary aspergillosis (CPA) was estimated as described previously $[1,14]$; the annual number of cases of pulmonary tuberculosis with cavities left after treatment $(\approx 12 \%)$ had a $22 \%$ risk of $\mathrm{CPA}$ in addition to a $2 \%$ risk in the remainder.

The prospective number of patients with allergic bronchopulmonary aspergillosis (ABPA) was calculated by applying a general rate of $2.5 \%$ of the number of adults with bronchial asthma (BA) in addition to $15 \%$ of the adult patients with cystic fibrosis (CF) [15]. The number of patients with asthma was derived from the reports of the Ministry of Health [9]. For estimation of the patients with severe asthma with fungal sensitisation (SAFS) it was assumed that $10 \%$ of patients with BA had a severe clinical course and 
$33 \%$ were sensitized to one of more fungi [16]. Data about ABPA frequency in CF patients were taken from the scientific literature, $~ 15 \%$ in adults [17]. About $21 \%$ of all patients with $\mathrm{CF}$ are adults [1].

To account for the morbidity from and burden of cryptococcal meningitis we used Russian data; cryptococcal meningoencephalitis developed in $0.44 \%$ patients with HIV-infection [1]. The number of cases of Pneumocystis pneumonia (PCP) was determined by assuming the risk extends over 2 years and $60 \%$ of HIV-infected patients with CD4+<0.2x10 $/ 1$ develop PCP [5].

\section{Results and discussion}

The population of the Republic of Uzbekistan in 2014 was 30,759,200 people [9]. The adults comprised $65.3 \%$ of the population, women $-50.1 \%$. The estimated gross domestic product per capita was USD $\$ 1,878$ in 2013 . The results received from the quantitative estimation of fungal diseases in the Republic of Uzbekistan are shown in table 1 .

\section{Mycosis of the scalp}

According to the data of RSRPMC in 2014, the total number of affected patients with tinea capitis was 7,307 or 23.8/100,000. Infection caused by Microsporum spp. accounted for 893 persons, while Trichophyton spp. was more common affecting 6,414 persons $(20.9 / 100,000)$. This is marked contrast to data in the Russian Federation where Microsporum infection of the scalp was much more common $(40.8 / 100,000)$ [1].

Table 1. Fungal diseases in the Republic of Uzbekistan (Incidence and prevalence estimates for 2014)

\begin{tabular}{|l|l|c|r|}
\hline \multicolumn{2}{|c|}{ Fungal diseases } & $\begin{array}{l}\text { Incidence per } \\
100,000 \text { people }\end{array}$ & Prevalence \\
\hline \multirow{4}{*}{ Acute } & Invasive aspergillosis & 4,8 & 1,521 \\
\cline { 2 - 4 } & Invasive candidiasis & 5,93 & 1,825 \\
\cline { 2 - 4 } & Cryptococcal meningitis & 0,21 & 65 \\
\cline { 2 - 4 } & Mucormycosis & 0,08 & 27 \\
\cline { 2 - 4 } & Pneumocystis pneumonia & 5,37 & 1,650 \\
\hline
\end{tabular}




\begin{tabular}{|l|l|c|r|}
\hline \multirow{4}{*}{ Subtotal } & Microsporia of scalp & 2,9 & 893 \\
\cline { 2 - 4 } & Trichophytosis of scalp & 20,85 & 6,414 \\
\hline \multirow{4}{*}{ Chronic } & Recurrent vulvovaginal candidiasis & 12,351 \\
\cline { 2 - 4 } & Recurrent candidiasis of the oral cavity & $3,339 *$ & 513,600 \\
\cline { 2 - 4 } & Recurrent oesophageal candidiasis & 16,09 & 4,950 \\
\cline { 2 - 4 } & Chronic pulmonary aspergillosis after TB & 6,72 & 2,066 \\
\cline { 2 - 4 } & Chronic pulmonary aspergillosis (all) & 2,1 & 647 \\
\cline { 2 - 4 } & Allergic bronchopulmonary aspergillosis & 2,86 & 879 \\
\cline { 2 - 4 } & Bronchial asthma with mycogenic & 3,73 & 1,147 \\
& sensibilization & & 524,627 \\
\hline Subtotal & \multicolumn{2}{|}{} & 536,978 \\
\hline Total
\end{tabular}

* - Incidence per 100,000 females, TB = pulmonary tuberculosis.

Candidiasis of mucous membranes

Recurrent vulvovaginal candidiasis (rVVC) is the most common mycotic disease in women. It is characterized by rather frequent recurrences, four or more times annually [5]. The calculations showed that in 2014 in the Republic 513,600 women suffered from this disease, which accounts for approximately 3,339 cases per 100,000 females. These data are similar to those of the Russian Federation $(3,481 / 100,000)$ [1] and higher than in Ukraine $(1,961 / 100,000)$ [7].

Uzbekistan registered 30,315 patients with HIV/AIDS in 2014 [11] which accounts for 99.4 persons per 100,000 population. In 2012, 11,000 were thought to have CD4 lymphocyte counts under $350 \times 10^{6} / \mathrm{L}$ [20]; a more recent estimate is unavailable. Consequently, the number of HIV-infection patients with oropharyngeal candidiasis was 4,950 (16.09 cases per 100,000 population), with oesophageal candidiasis $-2,066(6,72)$. The numbers affected are approximately half the incidence in the Russian Federation (42.4 and 9.42 respectively) [1]. In Ukraine the prevalence of oesophageal candidiasis is probably much higher $(30 / 100,000)$ [7].

\section{$\underline{\text { Invasive candidiasis }}$}

The number of patients hospitalized in Uzbekistan in 2014 accounted for 4,932,249 persons [9]. Among these patients, the total number of patients with invasive candidiasis in this period was $-1,825$ (5.93 cases per 100,000 population). These data 
are below those seen in the Russian Federation $(8.29 / 100,000$ population) and also correspond to Ukrainian and mean European parameters [1,7].

\section{Aspergillosis of the respiratory tract}

Hematological diseases, in particular AML, are an important risk factor for development of IA. According to the mean European parameters the risk of IA occurrence in this category of patients is equal to approximately 10\% [1]. According to the data of RIH and BT in the republic there were identified 189 patients with AML in 2014, and IA was diagnosed in 19 (10\%) of them. Taking into account that there were no organ transplantation procedures, the total annual incidence of IA cases was calculated by $50 \%$ of the IA cases in haematological patients were in AML $[19,20]$ plus $1.3 \%$ patients with chronic obstructive pulmonary disease (COPD) who were hospitalized $[3,21]$. The $1.3 \%$ rate is considerably lower than that found in southern China (3.9\%) [22], so we argue that the estimate is conservative. If genetic factors are of prime importance in IA development in COPD, then the chinese figure may be more reflective of reality, than the Spanish figure, as Uzbecks are more similar to chinese people genetically. Also we estimated likely burden of IA in the 1681 cases of lung cancer annually $(2.6 \%$ in a Japanese study [23]): $1681 * 2.6 \%=44$ cases/year. Finally, we estimated 1,521 patients with IA annually, or 4.8 cases per 100,000 population. The estimated IA annual incidence more than twice exceeds that of the Russian Federation (2.27/100,000 population) [1] and Ukraine (2.7/100,000 population) [7].

Chronic pulmonary aspergillosis (CPA) usually affects the patients suffering from chronic pulmonary diseases (tuberculosis, sarcoidosis, COPD, non-tuberculous mycobacterial infection, after pneumothorax and others). In Uzbekistan in 2014 the total number of patients with tuberculosis was 14,702 (47.8/100.000) [9]. The calculation of the possible cases of CPA was made by formula proposed by Denning D.W. and coauthors [14], in result there have been received 647 patients with CPA (2.1 cases per 100,000 population). In Russian Federation and Ukraine the given parameter was much higher [1,7]. Assuming that $33 \%$ of CPA cases are attributable to TB, the total CPA prevalence the Respublic is 1,941 affected patients. 


\section{$\underline{\text { Mucormycosis }}$}

The mucormycosis incidence in Uzbekistan in 2014 was calculated using data of RIH and BT about morbidity with AML. Mucormycosis frequency in the patients with AML accounted to 3.6\%, and AML was a risk factor for mucormycosis only in 25\% of cases [1]. Taking into account that in Uzbekistan in 2014 there were 189 cases of AML, the total number of mucormycosis patients was 27 , or 0,08 cases per 100,000 population, which is approximately half corresponding indices in the Russian Federation and Ukraine [1,7].

\section{Fungal asthma}

The prevalence of ABPA was estimated among those registered with bronchial asthma $(34,758)$ persons (170 per 100,000 adults) and with CF - 308 patients, of whom 65 were adult patients. Therefore we obtained an estimate of 879 patients with ABPA $(2.86 / 100,000)$. The estimate of those with SAFS was 1,147 in $2014(3.73 / 100,000)$. The prevalence of ABPA and SAFS appear to be considerably below those in the Russian Federation (122.5 and 161.7 per 100,000 population, respectively) [1] and Ukraine (62.5 and 82.3 per 100,000 population, respectively) [7], probably because asthma is under-diagnosed or not fully registered.

\section{Pneumocystis pneumonia and cryptococcal meningitis}

Pneumocystis pneumonia and cryptococcal meningitis seem to be important opportunistic infections in patients with HIV-infection. In 2015, an estimated 2,600 people died of AIDS [24]. In Uzbekistan, according to our calculations in 2014, there were 1,650 patients with Pneumocystis pneumonia, or 5.37 cases per 100,000 population. This parameter notably exceeds data in Russian Federation (0.99 cases per 100,000 population) [1], but lower than the parameter in Ukraine (13.5 cases per 100,000 population) [7]. The total number of cryptococcal meningoencephalitis in Uzbekistan in 2014 accounted for 65 cases $(0.21 / 100,000)$. In Russia and Ukraine the incidence of this mycosis appeared to be identical $(0.21$ and 0,22 per 100,000 population) $[1,7]$. 
This is the first attempt to estimate the total burden of fungal disease in the Republic. It shows that mycoses in Uzbekistan, as well as in many other countries, including the Russian Federation and Ukraine, are commoner than anticipated but lower than many other countries, with the exception of IA. These low rates could reflect lower populations at risk, undiagnosed populations at risk (such as COPD) and limited fungal diagnostic capacity in Uzbekistan. Establishment of a reference laboratory for medical mycology in Uzbekistan would be the most useful first step in addressing current deficiencies and uncertainties and will contribute towards achieving control of antibiotic resistance. Neither voriconazole, amphotericin B or flucytosine are available in Uzbekistan, limiting antifungal therapy treatment, and while itraconazole is available, it is expensive with a daily cost exceeding $\$ 4$ daily. 


\section{REFERENCES}

1. Klimko N, Kozlova Y, Khostelidi S, Shadrivova O, Borzova Y, Vasilieva N, Denning D.W. The burden of serious fungal diseases in Russia // Mycoses, 2015, 58 (Suppl. S5), 58-62.

2. Tilavberdiev Sh.A., Mavlyanova Sh.Z. Mycosis and HIV-infection. Med Jurnal Uzbekistana. - 2015, - №5. - P. 67-71.

3. Brown G.D., Denning D.W., Gow N.A., et al. Hidden killers: human fungal infections // Sci. Transl. Med. - 2012. - Vol. 19, №4 (165). - P.165rv13.

4. Bitar D, Lortholary O, Le Strat Y, Nicolau J, Coignard B, Tattevin P, Che D, Dromer F. Population-based analysis of invasive fungal infections, France, 2001-2010. Emerg Infect Dis 2014;20:1149-55.

5. LIFE (Leading international fungal education). An official site of organization - www.LIFE-worldwide.org (date accessed xxx)

6. http://life-worldwide.org/media-centre/article/life-serious-fungal-diseasesestimates-reach-5-billion-population-coverage (date accessed xxx)

7. Osmanov A, Denning DW. Burden of serious fungal infections in Ukraine. Mycoses 2015;58 Suppl 5:94-100.

8. Analytical information on the basic demographic parameters. https: // www.minzdrav.uz/news/detail.php? ID=36535 (date accessed xxx)

9. Statistical materials about activity of establishments of public health services of Republic of Uzbekistan in 2014. Tashkent. - 2015. - 296.

10. Foxman B, Muraglia R, Dietz JP et al. Prevalence of Recurrent Vulvovaginal Candidiasis in 5 European Countries and the United States: Results From an_Internet Panel Survey. Journal of Lower Genital Tract Disease, 2013. Vol 17,_Number 3, 340345

11. National report on a course of performance of the declaration about adherence to struggle with HIV/AIDS of the special session of general assembly UNO. Republic of Uzbekistan, Reporting period: January - December 2014, Tashkent, 2015. $24 \mathrm{p}$. 
12. Akhmedov B.R., Giyasov Kh.Z., Tashkulov M.M. Chronic obstructive pulmonary disease: computer tomography of high resolution in the diagnosis of emphysema and obliterating bronchiolitis // Molodoy uchyoniy. - 2014. - №3. - P. 137142.

13. Uzbekistan: profile of the country on a tuberculosis. WHO https: // extranet.who.int/sree/Reports?op=Replet\&name=WHO_HQ_Reports/G2/PROD/EXT/T BCountryProfile \&ISO2=UZ\&outtype=html\&LAN=RU (date accessed xxx)

14. Denning D.W., Pleuvry A., Cole D.C. Global burden of chronic pulmonary aspergillosis as a sequel to pulmonary tuberculosis // Bull World Health Organ. - 2011. - Vol. 1, №89 (12). - P. 864-72.

15. Denning D.W., Pleuvry A., Cole D.C. Global burden of allergic bronchopulmonary aspergillosis with asthma and its complication chronic pulmonary aspergillosis in adults // Med. Mycol. - 2012. - Vol. 4. - P. 1-10.

16. Denning D.W., O'Driscoll B.R., Hogaboam C.M., et al. The link between fungi and severe asthma: a summary of the evidence // Eur. Respir. J. - 2006. - Vol. 3. P. 615-26.

17. Armstead J, Morris J, Denning DW. Multi-country estimate of different manifestations of aspergillosis in cystic fibrosis. PLoS One 2014;9:e98502.

18. UNAIDS. UNAIDS Global Report 2013: UNAIDS report on the global AIDS epidemic 2013. http://www.unaids.org/sites/default/files/media_asset/UNAIDS_Global_Report_2013_e n_1.pdf (date accessed xxx)

19. Perkhofer, S., Lass-Florl, C., Hell, M., Russ, G., Krause, R., Honigl, M., et al (2010) The Nationwide Austrian Aspergillus Registry: a prospective data collection on epidemiology, therapy and outcome of invasive mould infections in immunocompromised and/or immunosuppressed patients. Int J Antimicrob Agents 36: 531-536.

20. Lortholary, O., Gangneux, J.P., Sitbon, K., Lebeau, B., de Monbrison, F., Le Strat, Y., et al (2011) Epidemiological trends in invasive aspergillosis in France: the SAIF network (2005-2007). Clin Microbiol Infect 17: 1882-1889. 
21. Guinea J, Torres-Narbona M, Gijon P, Munoz P, Pozo F, Pelaez T, et al. Pulmonary aspergillosis in patients with chronic obstructive pulmonary disease: incidence, risk factors, and outcome. Clin Microbiol Infect, 2010; 16:870-7.

22. Xu H, Li L, Huang WJ, Wang LX, Li WF, Yuan WF. Invasive pulmonary aspergillosis in patients with chronic obstructive pulmonary disease: a case control study from China. Clin Microbiol Infect 2012;18:403-8.

23. Yan X, Li M, Jiang M, Zou L, Luo F and Jiang Y. Clinical Characteristics of 45 Patients with Invasive Pulmonary Aspergillosis: Retrospective Analysis of 1711 Lung Cancer Cases. Cancer 2009; 115:5018-25.

24. http://www.unaids.org/en/regionscountries/countries/uzbekistan (date accessed $\mathrm{xxx}$ ) 